\title{
Water Seal Effect Evaluation of Underground Crude Oil Storage Caverns on Operation Period
}

\author{
Hongmin Feng ${ }^{1, ~ a}$, Binghua Zhou ${ }^{2, b}{ }^{*}$, Jianyi Liang ${ }^{3, \mathrm{c}}$ and Zhiqiang $\mathrm{Li}^{2, \mathrm{~d}}$ \\ ${ }^{1}$ Engineering Dept, Sinopec, Beijing 100728, China \\ ${ }^{2}$ Geotechnical and Structural Engineering Research Center, Shandong University, Jinan 250061, \\ China \\ ${ }^{3}$ Huangdao Oil Reserve Base Limited Company, Qingdao 266426, China \\ afenghongmin@163.com, bwmzhl888@163.com, cwgchdljy@163.com, dizqhlxy@163.com
}

Keywords: underground water seal oil caverns, operation period, field monitoring, water seal effect.

\begin{abstract}
Water seal effect of an underground crude oil storage caverns is the key to the normal operation. This paper analyzes the monitoring data of the water level of water curtain, supplementary water capacity of water curtain, ground water, pore water pressure of main cavity, seepage volume of main cavity, temperature of main cavity collected in the trial production of underground crude oil storage caverns. According to the data analysis, the timely water supplement of water screen system ensures that the water level of water curtain in the normal operation reaches the lowest hydraulic boundary, which proves the water seal effect is reliable. And the independence of water seal resistance between main cavities is poor, and the liquid pressure difference and pressure difference should be decreased as far as possible.
\end{abstract}

\section{Introduction}

The water seal effect of an underground crude oil storage caverns is build in a rock mass below the stable groundwater level. Before excavate the cave, groundwater penetrates deep into the formation through joint fissures and completely filled with the gap in the rock. When underground water seal oil caverns is excavated, the fissure water in the surrounding rock flows to the hollowed out cavern and filled with the cavern [1-2]. There will be some pressure around the oil pressure after the oil injected into the chamber. Therefore, The storage medium does not seep from the fissure when the osmotic pressure of the water in the fissure is greater than the storage medium pressure on any oil surface. At the same time, The water flowing into the chamber is along the wall that pool the bottom of the hole to form a " filter blanket "[3-4]. The water curtain system of the underground water seal oil caverns can improve the hydrological flow form of the rock fissures around the oil reservoirs and provide artificial recharge system to maintain high water pressure. If the underground cavern's water seal effect is worse and the groundwater level is unstable that can change groundwater pressure and easily lead to oil leakage. 


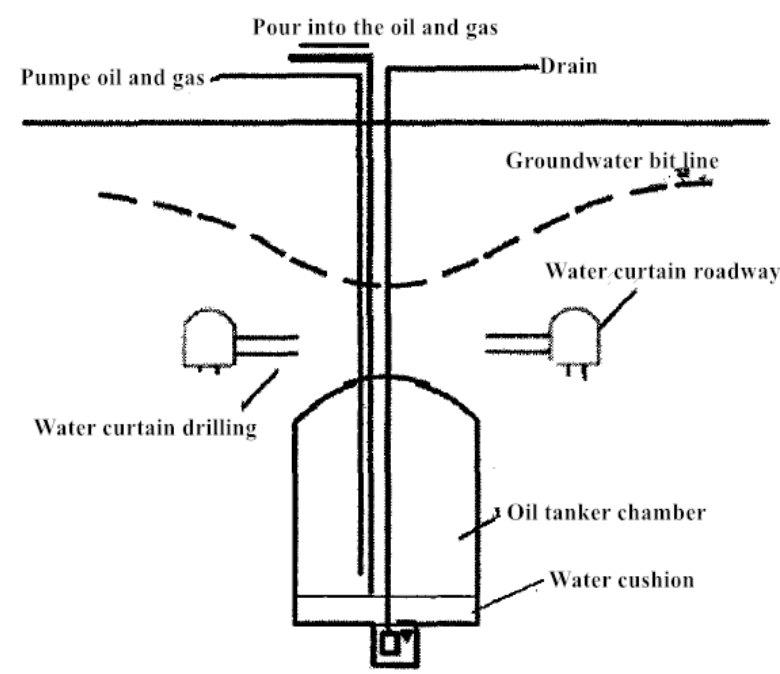

Fig. 1 The oil storage principle for water seal effect of an underground crude oil storage caverns

\section{Engineering Situation}

The site of a large underground water seal oil caverns is a low hilly landform which has built. The average elevation of the ground is $220 \mathrm{~m}$. The highest point elevation is $350.9 \mathrm{~m}$. The lowest point is $97.50 \mathrm{~m}$. The reservoir area is north by west. The reservoir is about $838 \mathrm{~m}$ long from north to south and the reservoir is about $600 \mathrm{~m}$ from east to west. The oil depot is mainly composed of oil storage tank and drencher system. Oil storage tank is composed by 3 groups of tanks, each measuring $20 \mathrm{~m} \times 30 \mathrm{~m}$, water curtain system is composed by 5 water curtain tunnels, measuring $5 \times 4.5$, and 529 water curtain holes whose aperture is $120 \mathrm{~mm}$, oil storage tank needs to undertake the water quality complement requested by water seal, the balance of hydraulic pressure 8 the stability of groundwater level. As show in fig. 2 , the water curtain roadway is vertically arranged with the main hole chamber, and the water curtain hole is parallel with the main hole chamber covering the whole hole.

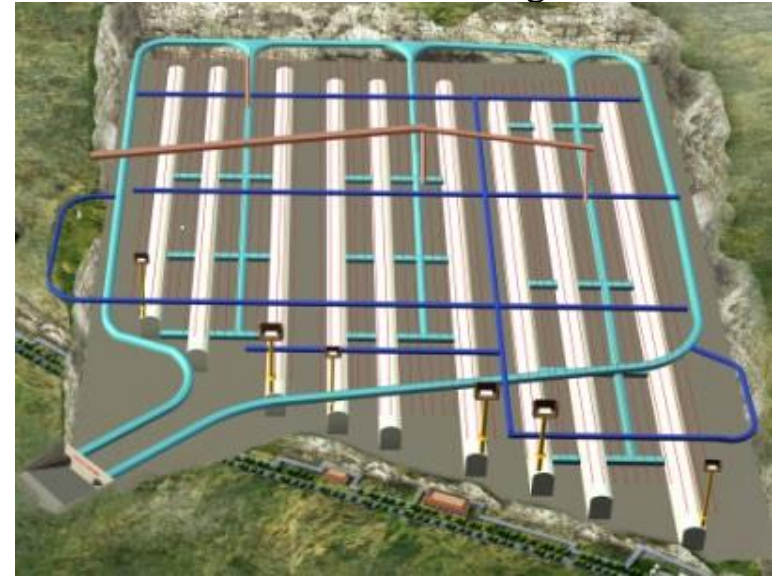

Fig. 2 Underground water seal oil caverns area plan layout

\section{Water seal effect evaluation of an underground crude oil storage caverns}

The operation of underground crude oil storage caverns is mainly carried out around the pilot production running. The water level of water curtain, groundwater level, water supply of water curtain system and interstitial pressure were observed.

\subsection{The water level of water curtain.}

The water level of the water curtain system shall meet the minimum hydraulic boundary of $38 \mathrm{~m}$ in order to ensure the water seal condition of underground crude oil storage caverns. Before the trial production is not started, the water curtain system water source mainly come from the main cavern fissure seepage. At this point the underground main chamber cracks seepage into the main chamber 
without any pollution and the greatest degree of water resources. After the trial production into the oil, the water curtain system water supply mainly from the municipal water supply. As show in figure 3 [5-8].

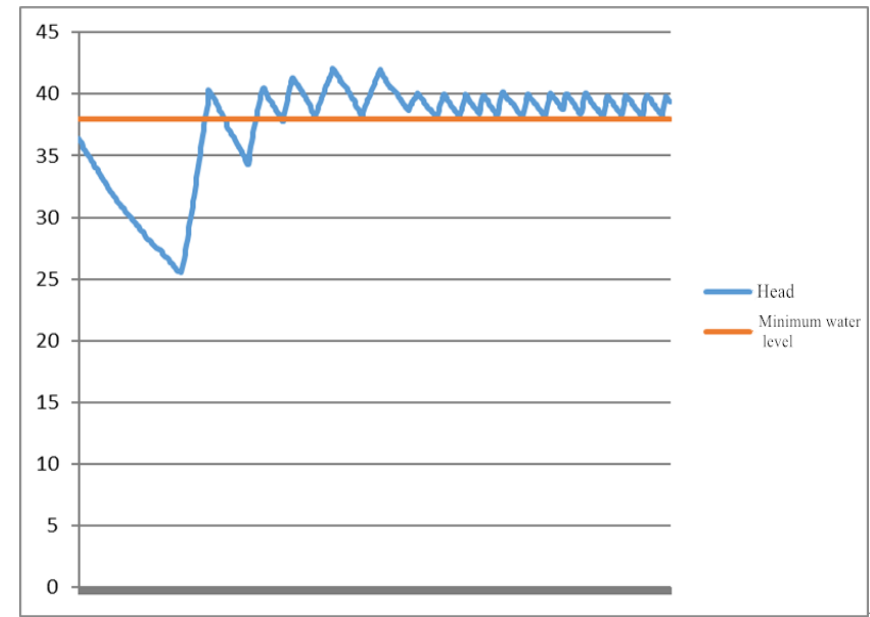

Fig. 3 The water level of water curtain

\subsection{Interstitial pressure of main chamber}

According to the osmometer data of the oil-bearing main hole at $-20 \mathrm{msl}$, it is shown that the three pore water pressure at the height of $+5 \mathrm{~m},-5 \mathrm{~m}$ and $-15 \mathrm{~m}$ can fully meet the boundary condition. It fundamentally meet the underground hole of the water seal. Main hole between the pillars buried osmometer. With the trial production into the oil, the main hole work pressure will increase and $-25 \mathrm{~m}$, $-35 \mathrm{~m},-45 \mathrm{~m}$ pore pressure also will rise. This also better reflect the penetration between the joint fracture of the rock mass and the main chamber. However, the water curtain system in the process of water filling, the change is not obvious. It reflects the poor water retention of the pillars between the main chamber and the independence of the cave is poor.

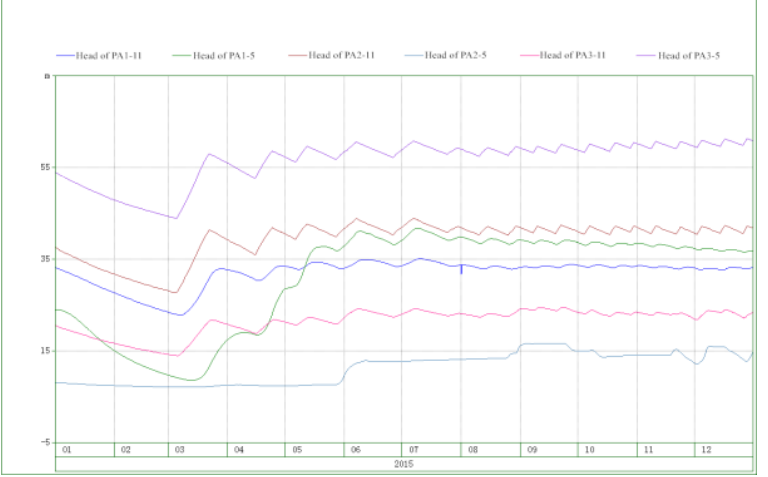

(a) The change map of A hole pore water pressure at - 5m elevation

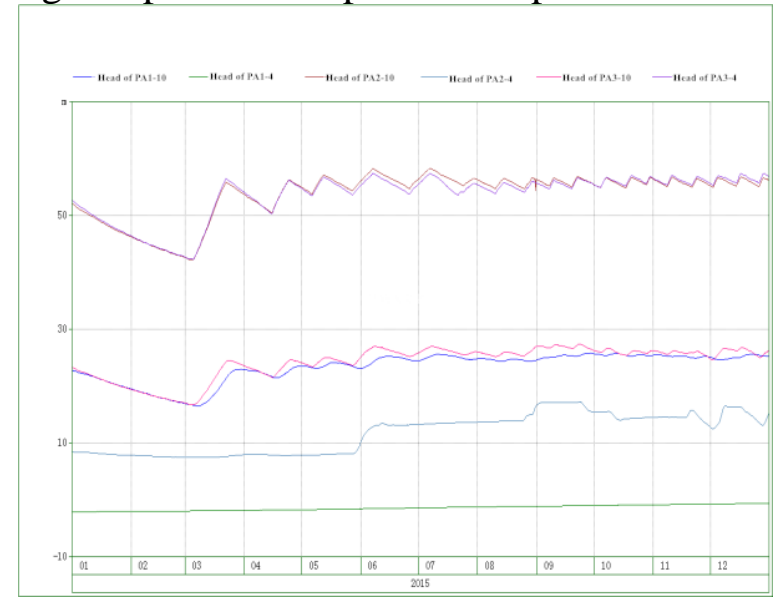

(b) The change map of A hole pore water pressure at - 15m elevation 


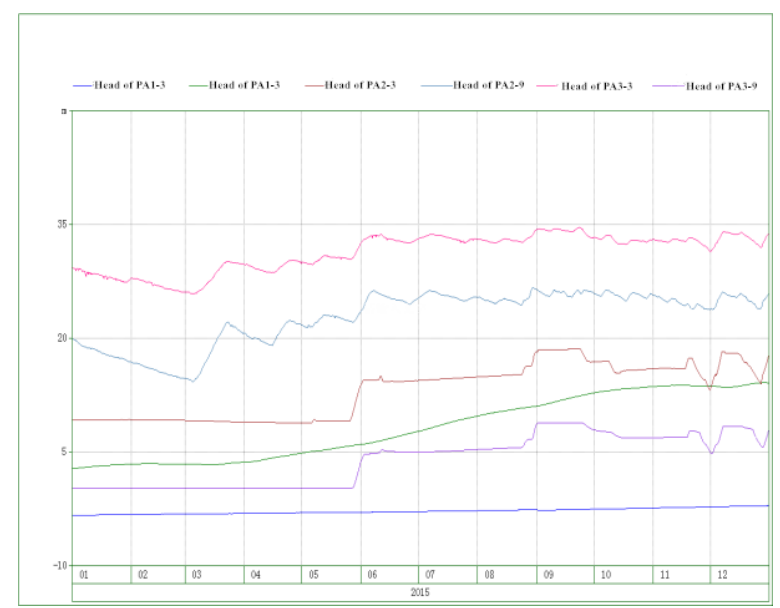

(c) The change map of A hole pore water pressure at - $25 \mathrm{~m}$ elevation

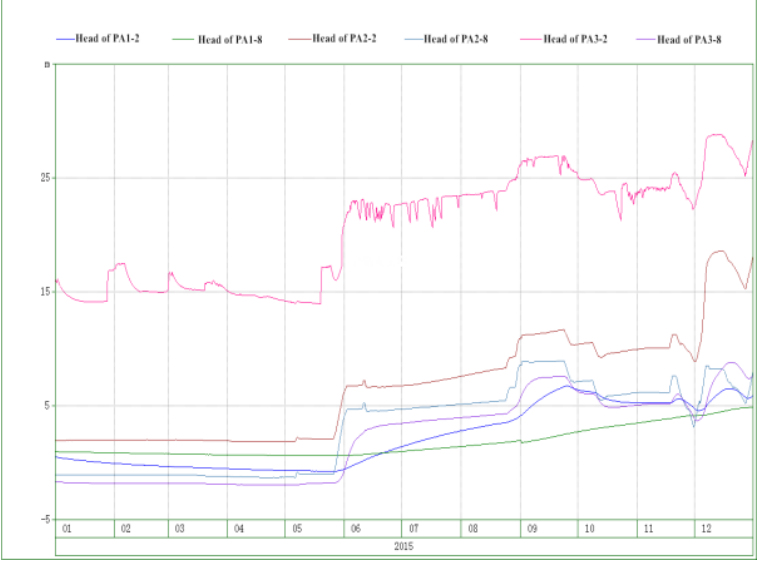

(d) The change map of A hole pore water pressure at - 35m elevation

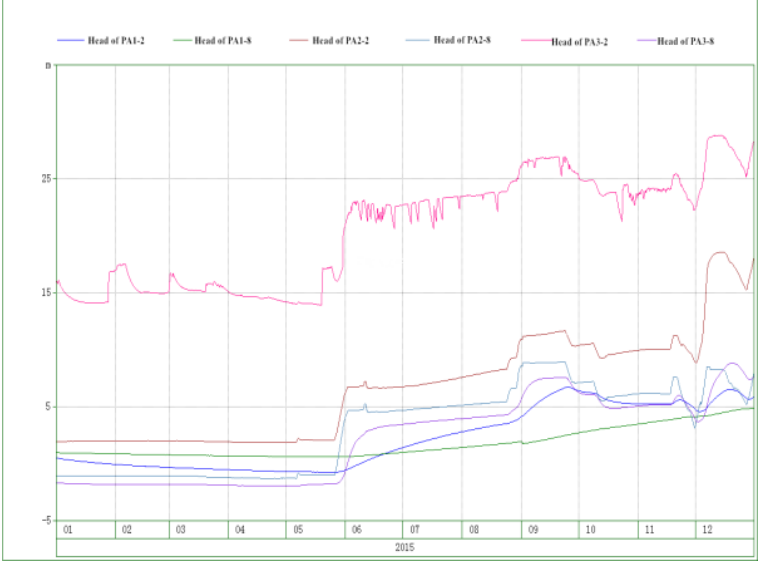

(e) The change map of A hole pore water pressure at - $45 \mathrm{~m}$ elevation

Fig. 4 The change map of A hole pore water pressure

\section{Conclusion}

The key to the normal production operation of the cave is water seal effect evaluation of an underground crude oil storage caverns. This paper analyzes the monitoring data of the water level of water curtain, supplementary water capacity of water curtain, ground water, pore water pressure of main cavity, seepage volume of main cavity, and temperature of main cavity collected in the trial production of underground crude oil storage caverns. The reliability of the effect of water seal in underground oil seal is demonstrated. This paper gets the following conclusions: 
(1) The water seal effect of the groundwater closet is reliable. The water curtain system provides an effective recharge of groundwater. During the trial production, the water level of the water curtain reached the minimum hydraulic boundary, which ensured the normal production operation.

(2) The independence of the cave is poor. During the production operation, we need to minimize the gap between the chamber and the pressure difference.

\section{References}

[1] Xue Y G, Li S C, Qiu D H, et al. A new evaluation method for site selection of large underground water-sealed petroleum storage depots [J]. Science China Technological Sciences, 2015, 58(6):967-978.

[2] Wang Z C, Zhang Z J, Li S C, et al. Assessment of inter-cavern containment property for underground oil storage caverns using discrete fracture networks [J]. Journal of Shandong University (Engineering Science), 2016, 46(2):94-100. (in chinese)

[3] Ma X Y, Zhang L, Su Q, et al. Optimum design research on water curtain system in large underground water-sealed oil storage cavern [J]. Rock and Soil Mechanics, 2016, 37(3):776-782. (in chinese)

[4] Ping Y, Wang Z C, Li S C, et al. Water seal effect evaluation of underground crude oil storage caverns around rock mass with random joints [J]. Rock and Soil Mechanics, 2014(3):811-819. (in chinese)

[5] Li J Y, Peng Z H, Zhang J, et al. Preliminary evaluation of sealing condition for water seal underground storage [J]. West-china Exploration Engineering, 2012, 24(5):15-17. (in chinese)

[6] Hu D X, Cheng F J et al. Monitoring and control of groundwater in water sealing cavern [J]. Site Investigation Science and Technology | Site Invest Sci Technol, 2009(6):43-45. (in chinese)

[7] Feng S R, Jiang Z M, Zhang J L, et al. Water sealing criteria for underground oil storage in unlined rock caverns [J]. Chinese Journal of Geotechnical Engineering, 2014, 36(5):886-891. (in chinese)

[8] Hong K R. Development and application of construction technologies for underground water-sealed energy storage caverns [J]. Tunnel Construction, 2014, 34(3):188-197. (in chinese) 